Review paper

\title{
A review of antenna designs for percutaneous microwave ablation
}

\author{
Hangming Huang ${ }^{\mathrm{a}}$, Lifeng Zhang ${ }^{\mathrm{b}}$, Michael A.J. Moser ${ }^{\mathrm{c}}$, Wenjun Zhang ${ }^{\mathrm{d}}$, Bing Zhang ${ }^{\mathrm{a}, 1, *}$ \\ ${ }^{a}$ Energy-based Tumor Ablation Laboratory, School of Mechatronic Engineering and Automation, Shanghai University, Shanghai, China \\ ${ }^{\mathrm{b}}$ Department of General Surgery, the First Affiliated Hospital of Soochow University,Soochow University, Jiangsu, China \\ ${ }^{\mathrm{c}}$ Department of Surgery, College of Medicine, University of Saskatchewan, Saskatoon, Canada \\ ${ }^{\mathrm{d}}$ Division of Biomedical Engineering, College of Engineering, University of Saskatchewan, Saskatoon, Canada
}

\section{A R T I C L E I N F O}

\section{Keywords:}

Microwave ablation

Microwave antenna

Antenna design

Backward heating

Tumor ablation

\begin{abstract}
A B S T R A C T
Microwave (MW) antenna is a key element in microwave ablation (MWA) treatments as the means that energy is delivered in a focused manner to the tumor and its surrounding area. The energy delivered results in a rise in temperature to a lethal level, resulting in cell death in the ablation zone. The delivery of energy and hence the success of MWA is closely dependent on the structure of the antennas. Therefore, three design criteria, such as expected ablation zone pattern, efficiency of energy delivery, and minimization of the diameter of the antennas have been the focus along the evolution of the MW antenna. To further improve the performance of MWA in the treatment of various tumors through inventing novel antennas, this article reviews the state-of-the-art and summarizes the development of MW antenna designs regarding the three design criteria.
\end{abstract}

\section{Introduction}

Microwave ablation (MWA) is one of the energy-based minimally invasive modalities in the treatment of various tumors, such as liver tumors [1], lung tumors [2], renal tumors [3], and bone tumors [4]. In general, tumor ablation in MWA is achieved with one or more MW antennas inserted into the targeted tissue percutaneously under the guidance of an image-guided device [5-10]. High-frequency electromagnetic energy (commercially available at $915 \mathrm{MHz}$ or $2.45 \mathrm{GHz}$ ) generated by a microwave power generator is transferred through a coaxial cable as an antenna into surrounding tissues to cause a rise in temperature to $60{ }^{\circ} \mathrm{C}$ or above, which leads to protein denaturation and coagulative necrosis [11-17]. It is widely accepted that the heat energy is due to the agitation of polar molecules (i.e., water molecules) in the tissue caused by the high-frequency electromagnetic energy [18-20].

The design of a MW antenna plays a critical role in achieving an efficient MW power transmission and hence a successful tumor ablation. At present, the most widely used antenna is based on the semi-rigid coaxial cable, which generally consists of the inner conductor, dielectric, and outer conductor, as shown in Fig. 1. Such a design seems fitting for MWA due to its cylindrical geometry and small diameter.

In the MWA, an ideal antenna would be the one that can achieve the expected ablation zone pattern (size and shape) with a high efficiency in energy transmission and low invasiveness to patients. Therefore, the expected ablation zone pattern, high efficiency, and low invasiveness are three design criteria that are used to evaluate the design of antennas.

Obtaining an expected ablation zone pattern means the successful ablation of tumor with the minimal damage to surrounding normal tissues. There exist both omni-directional and directional radiation pattern approaches for delivery of the microwave energy in literature. As for omni-directional antennas, energy can be transferred into tissues in all directions around the antenna, which was usually used to eradicate tumors in a regular shape (e.g., spherical or elliptical) [21-23]. On the other hand, a directional antenna that affords spatial control of the energy deposition may be a better choice when tumors are in proximity to critical structures, such as blood vessels or bile ducts.

The transmission efficiency of the antenna represents how much energy is transferred into tissues compared with the total energy. A high efficiency is preferred in antenna design, as this means less energy loss (i.e., energy reflected to the power generator) inside the antenna. This energy reflection is usually caused by the impedance mismatching. It can increase the heating of the antenna itself and the tissues in very close proximity, including the proximally up the shaft which can lead to injury of healthy tissues.

Furthermore, with the concept of minimally invasive ablation, an antenna with a small size is more desirable when considering the

\footnotetext{
* Corresponding author.

E-mail address: bingzhang84@shu.edu.cn (B. Zhang).

1 http://orcid.org/0000-0001-5650-2518.
} 


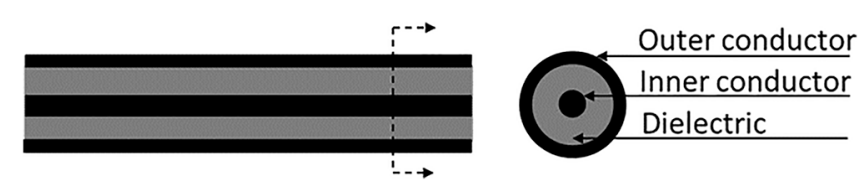

Fig. 1. The axial view and transverse view of the semi-rigid coaxial cable (grey: dielectric, black: conductor).

comfort and safety of patients during MWA procedures.

To date, a plethora of research efforts have been directed towards the design of MW antennas for achieving the three above-mentioned objectives (expected ablation zone pattern, high efficiency, and low invasiveness). The dipole [24], monopole [25], and slot antennas [26] are three basic designs. However, the ablation zone patterns of those antennas are negatively affected by the backward heating along the shaft of the antennas caused by leaking currents because of the unbalanced antenna structure [27-29]. As a result, "comet-shaped" ablation zones are usually generated in MWA, which is obviously not an optimal ablation zone pattern for sphere- or ellipsoid-like tumors. The tail of the comet inevitably damages the normal tissues along the shaft of MW antenna. Therefore, modified designs have been proposed to improve radiation properties of antennas by adding a choke or sleeve outside the antennas [30-34], which can effectively suppress the reverse heating. Unfortunately, this is at the expense of an increase in the diameter of the antenna. To keep the antenna as small as possible, some researchers have proposed to modify the inner structure of antennas such that the sleeves or chokes are implemented inside the antenna [35-37]. Further studies showed that the backward heating can be also restrained by adding antenna slots or a cooling system, optimizing the outer conductor structure, or changing the frequency of electromagnetic energy [38-41]. The directional ablation zone is another practical ablation zone pattern for MWA in clinical practice. Compared with an antenna that can generate an omni-directional ablation zone pattern, a directional antenna can simplify the treatment and offer protection to normal tissues when tumors are adjacent to vulnerable biological structures $[42,43]$. When the efficiency of the antenna is not satisfactory by just optimizing the antenna structural parameters, an impedance matching network can be implemented in the design of antennas as a means to further improve the efficacy $[41,44,45]$.

There have been several published reviews of MWA, such as $[11,29,46-48]$. However, considerable progress has been made in MWA in last few years, especially with respect to the design of antennas, which is the primary focus of this paper. It is noteworthy that Fallahi et al. [29] also reviewed the antenna designs in MWA, focusing on various antenna designs for site-specific thermal ablation of tissues. However, some new antenna designs reported in recent years (e.g., antennas with double chokes, ten-slot antennas, and tri-slot antennas) were not mentioned in their review. The methods to address the issues in the antenna design were not discussed thoroughly in literature. Therefore, this review paper updates the state-of-the-art of antenna designs in MWA and discusses the problems and solutions in the antenna designs, specifically in solving the three above-mentioned issues of MWA. It should be noted that results from clinical trials were not included in this review. If one is looking for information about the clinical performance and trials related to MWA, several detailed reports, for example [49-57], are available.

\section{Principle of MWA}

MWA is a physical intervention in which polar molecules (e.g., water) are forced to oscillate under an externally applied high frequency electromagnetic field to generate dielectric heating. This heat energy, in turn, raises the temperature of the tissues to a lethal level to cause the coagulative necrosis of cells. Therefore, MWA is a coupled problem that includes the electromagnetic wave conduction and heat transfer in biological tissues.
The propagation and absorption of electromagnetic wave in tissue can be described by the following Maxwell's equations [58-60]:

$$
\left\{\begin{array}{l}
\nabla \times E=-\frac{\partial \mathbf{B}}{\partial t} \\
\nabla \times H=J+\frac{\partial \mathbf{D}}{\partial t} \\
\nabla \cdot B=0 \\
\nabla \cdot D=\rho_{\text {free }}
\end{array}\right.
$$

where $\mathbf{E}(\mathrm{V} / \mathrm{m})$ is the electric field, $\mathbf{B}\left(\mathrm{Wb} / \mathrm{m}^{2}\right)$ is the magnetic flux density, $\mathbf{H}(\mathrm{A} / \mathrm{m})$ is the magnetic field, $\mathbf{J}\left(\mathrm{A} / \mathrm{m}^{2}\right)$ is the current density, $\mathbf{D}$ $\left(\mathrm{C} / \mathrm{m}^{2}\right)$ is the electric flux density, and $\rho_{\text {free }}\left(\mathrm{C} / \mathrm{m}^{2}\right)$ is the free charge density,

The transmission of electromagnetic energy is determined by the magnetic permeability and dielectric permittivity of the surrounding media. Because the magnetic permeability of biological tissues is approximately equal, the propagation of electromagnetic energy is mainly determined by the dielectric permittivity of tissues. The dielectric permittivity of various tissues is different and contains the real and imaginary components, where the real part represents the ability to store electrical energy relative to vacuum, and the imaginary part represents the loss of microwave energy in the medium.

The complex relative permittivity of the tissue $\left(\varepsilon_{r}^{*}\right)$ is often defined as $[61,62]$ :

$\varepsilon_{r}^{*}=\varepsilon_{r}-\frac{j \sigma_{c}}{\omega \varepsilon_{0}}$

where $\varepsilon_{r}$ is the relative permittivity of biologic tissue, $\sigma_{c}(\mathrm{~S} / \mathrm{m})$ is the electrical conductivity, $\omega(\mathrm{rad} / \mathrm{s})$ is the angular frequency and $\varepsilon_{0}$ is the permittivity of vacuum. It has been found that the relative permittivity and electrical conductivity of biological tissues are dependent on frequency, temperature, and water content [63-65]. Therefore, taking these factors into consideration is of critical importance to develop an accurate computer model for MWA.

The physics of heat transfer in biological tissues can be described by the Pennes' bio-heat transfer equation, as follows [66]:

$\rho C\left(\frac{\partial T}{\partial t}\right)=\nabla \cdot(k \nabla T)-Q_{b}+Q_{m}+Q_{e}$

where $\rho\left(\mathrm{kg} / \mathrm{m}^{3}\right)$ is the tissue density, $C(\mathrm{~J} /(\mathrm{kg} \cdot \mathrm{K}))$ is the tissue specific heat, $T(\mathrm{~K})$ is the tissue temperature, $k(\mathrm{~W} /(\mathrm{m} \cdot \mathrm{K}))$ is the thermal conductivity that is also a temperature-dependent variable $[67,68], Q_{b}(\mathrm{~W} /$ $\mathrm{m}^{3}$ ) denotes heat loss by blood perfusion, $Q_{m}\left(\mathrm{~W} / \mathrm{m}^{3}\right)$ is the metabolic heat generation, and $Q_{e}\left(\mathrm{~W} / \mathrm{m}^{3}\right)$ is the external heat source by MWA defined as $[69,70]$ :

$Q_{e}=\frac{1}{2} \sigma_{c}|\mathbf{E}|^{2}$

where $|\mathbf{E}|(\mathrm{V} / \mathrm{m})$ is the magnitude of the electrical field.

There are two widely accepted models to predict the ablation zone, namely the temperature threshold model and the Arrhenius damage model $[61,71]$. The temperature threshold model is the commonly-used method for predicting tissue death in MWA, which is based on the mechanisms of instantaneous cell death due to coagulation necrosis. However, there is no general consensus on the temperature to be used. The temperature thresholds in the range of $50-60{ }^{\circ} \mathrm{C}$ have been used as indicators of treatment endpoint in different literature [72], and the ablation time also needs to be considered while the threshold at a relative low temperature is used, like $50-54{ }^{\circ} \mathrm{C}$. Due to the death of biological tissues in MWA is related to not only the treatment temperature and ablation time but also the tissue type, the Arrhenius damage model has also been used in the computer simulation [73,74]. It is noteworthy that a shrinkage up to about $30 \%$ can occur in the ablation 
(A)

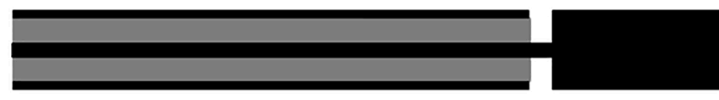

(C)

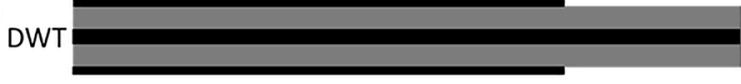

AWT

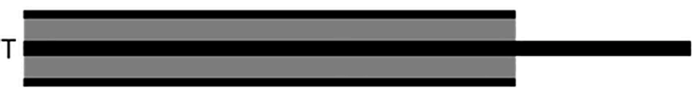

(D)

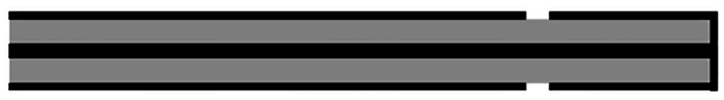

(B)

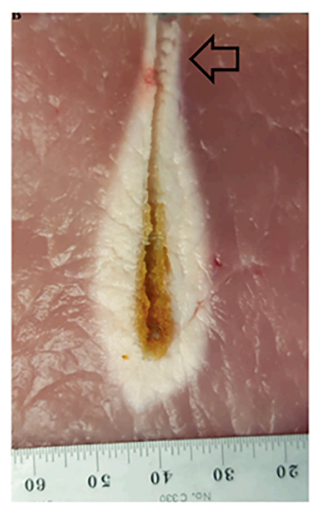

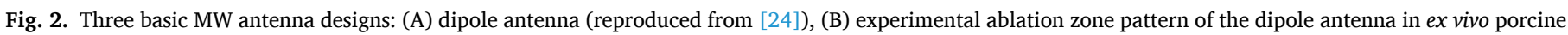

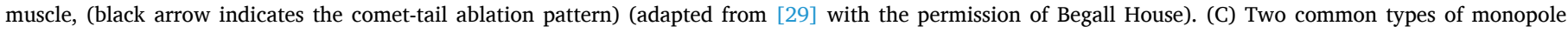
antennas (reproduced from [47,91]), and (D) slot antenna (reproduced from [29]).

zone of liver tissues during MWA owing to the high temperature induced [75-77]. This phenomenon can affect the accurate estimation of the ablation zone, leading to failure in achieving the expected ablation zone patterns. An ex vivo liver tissue shrinkage predictive model has been proposed and validated in literature $[78,79]$. Therefore, taking the tissue contraction during MWA treatment into account is also critical for the accuracy of numerical simulations in the prediction of ablation zone.

\section{MW antenna properties}

To describe the magnitude of the wavelength that propagates through the tissue, the effective wavelength $\left(\lambda_{\text {eff }}\right)$ is introduced, which is defined as $[80,81]$ :

$\lambda_{\text {eff }}=\frac{c}{f \sqrt{\varepsilon_{r}}}$

where $c(\mathrm{~m} / \mathrm{s})$ is the speed of light in free space, $f(\mathrm{~Hz})$ is the operating frequency.

There are two critical factors commonly used to describe the performance of the designed MW antennas during MWA procedures: the reflection coefficient $\left(S_{11}\right)$ and the specific absorption rate (SAR) [47]. $S_{11}$ represents how much the electromagnetic power is reflected to the power source compared with the total input power. In general, this factor is used to evaluate the power transmission efficiency of an antenna, which can be given as [82-84]:

$S_{11}=20 \log _{10}(|\Gamma|)=10 \log _{10}\left(\frac{P_{r}}{P_{\text {in }}}\right)$

where $\Gamma$ is a complex-valued reflection coefficient, which can be expressed in the logarithmic scale by the $S_{11}$-parameter $(\mathrm{dB}), P_{r}(\mathrm{~W})$ and $P_{\text {in }}(\mathrm{W})$ indicate the reflected power and the input power, respectively.

SAR represents the amount of electromagnetic energy absorbed by per unit mass of tissues. It can be defined as [85-90]:

$\mathrm{SAR}=\frac{\sigma_{c}}{2 \rho}|\mathbf{E}|^{2}$

Generally, a highly localized SAR pattern around the tip of the antenna is always required in the procedure of tumor ablation. Because the electromagnetic energy turns into thermal energy that heats the tissues to a lethal level of temperature, SAR pattern can also be used as an index of tumor ablation performance of the designed MW antenna.

To sum up, combining the MWA principles and antenna properties, we can computationally model and simulate the MWA procedure to shorten the amount of time and reduce the cost involved in the development cycle of a novel antenna. The novel antenna prototype can then be manufactured for the ex vivo and/or in vivo experiment validation, facilitating the translation of a newly-designed antenna into clinical practice.

\section{Three basic MW antenna types}

As shown in Fig. 2, dipole, monopole, and slot antennas are three basic coaxial-based ones, from which most of the commercially available MW antennas were developed [29].

The dipole antenna (Fig. 2A) was proposed by adding a metal block at the distal end of the coaxial cable and electrically connected to the inner conductor. The infinitesimal gap between the coaxial cable and the metal block is the location where the radiation intensity is strongest, acting as the effective source for propagating electromagnetic waves $[47,92]$. One arm of the dipole is the metal block in a short axial length, and the other is the outer conductor of the coaxial cable in a relatively long axial length. This unbalanced feature easily makes this antenna with the so-called 'leaking current', which travels from the gap to the MW power generator along the outer surface of the outer conductor. The tissues along the shaft of the antenna can be thermally damaged by the leaking current, which has been called 'the backward heating' problem [93]. As a result, the ablation zone pattern can be affected by the backward heating, leading to the undesired damage to surrounding normal tissues with a 'comet-tail' shape of ablation zone pattern, as shown in Fig. 2B. At the same time, the thermal damage area is dependent on the insertion depth of the antenna with the existence of the backward heating.

Two conventional types of monopole antenna are shown in Fig. 2C. The dielectric wrapped tip monopole antenna (DWT) is created by extending the inner conductor and dielectric of semi-rigid coaxial cable outwards while keeping the length of the outer conductor unchanged. DWT becomes the so-called air wrapped tip (AWT) monopole antenna when only the inner conductor is extended all the way to the tip. In addition, the inner conductor of the AWT can be modified for other purposes. For instance, a helical structure of the inner conductor allows for a shorter antenna [41]. This is because the phase velocity of the electromagnetic wave propagating down the axis of a helical structure occurs more slowly than that along a straight wire. As a result, the wavelength of waveguide becomes shorter and the size of the antenna is greatly reduced.

On the other hand, the helical structure acts as an inductor, presenting an inductive impedance during the transmission of MW energy, which can help to neutralize the inherent capacitive reactance of the antenna itself. Mazen et al. [94] demonstrated that the transmission efficiency of the DWT was better than that of the AWT, because compared to air used in an AWT, the dielectric material, with its higher relative permittivity, can improve the impedance between the antenna and the tissues, which in turn improves the matching between the 
(A)

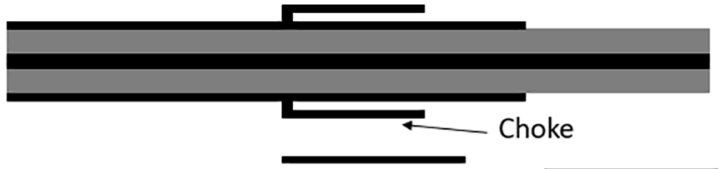

(B)

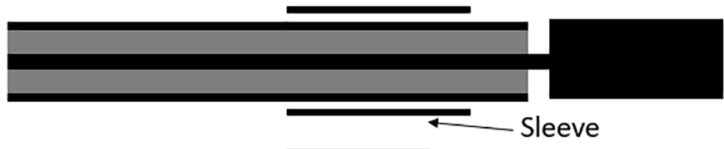

(C)

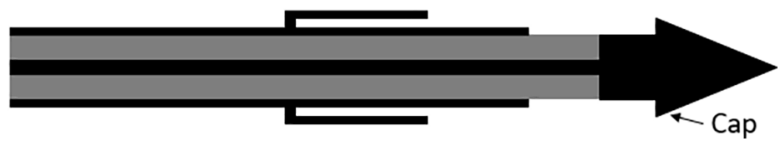

Fig. 3. Examples of antennas with choke, sleeve and cap: (A) monopole antenna with the choke (reproduced from [97]), (B) dipole antenna with the sleeve (reproduced from [31]), (C) cap-choked antenna (reproduced from [99]).

antenna and the generator [94]. Some simulation results showed that both designs can achieve good energy deposition at the active tip of the antennas $[25,91]$. However, they all have the backward heating problem as the dipole antenna does.

The slot antenna (Fig. 2D) is another basic MW antenna, which is characterized by a soldering connection between the inner and outer conductors at the end of the semi-rigid coaxial cable. A slot far smaller (less than one tenth) than the effective wavelength is cut through the outer conductor near the soldering point to allow electromagnetic wave propagation into the tissues. The slot antenna is usually wrapped with a catheter for protection during the application, but the research has shown that increasing the catheter thickness could reduce the power localization [95]. It is worth mentioning that this slot antenna also has the backward heating problem, like the dipole and monopole antennas [96].

In conclusion, though these three basic antennas can make the electromagnetic energy more localized around the active tip of the antennas and heat up target tissues to a lethal level, they all have the backward heating problem caused by the leaking currents. This backward heating can cause thermal damage to surrounding normal tissues along the axial direction of the antenna, leading to less focused ablation zone patterns.

\section{Designs to overcome the backward heating}

Various designs have been proposed to date to overcome the backward heating issue of MW antennas in literature. Those designs can mainly be classified into two categories: 1) the optimization of the physical structure and 2) the optimization of the operating frequency of MW antennas. Five state-of-the-art designs in current literature were systematically reviewed on the mechanisms and performances on overcoming the problem of backward heating in this paper.

\section{Addition of the sleeve, choke, or cap}

As shown in Fig. 3A, Nevels et al. [97] found that the leaking current can be restrained by electrically connecting a choke to the outer conductor of monopole MW antennas, leading to more energy localized around the active tip of the antennas [98]. Hulusi et al. [28] demonstrated that with a length of about $\lambda_{\text {eff }} / 4$, the choke results in an infinite impedance at its open end to confine the currents on the outer conductor to the region between the choke and the end of the line. The same effect was also found in the work of Yang et al. [31] by adding a metal floating sleeve, which is electrically isolated from the outer conductor of the dipole antenna body, as shown in Fig. 3B. The result of this strategy is that the MW energy propagates into the tissues in two ways. Most of the wave propagates directly into the tissues through the gap at the antenna tip, while minimal power propagates through the Teflon gap between
(A)

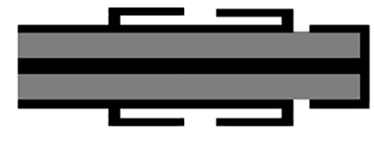

(B)

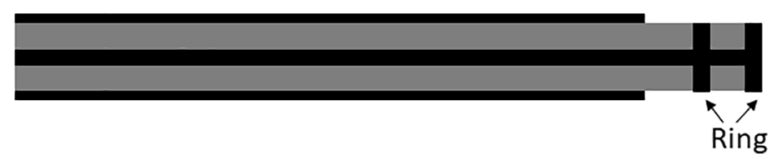

Fig. 4. (A) Slot antenna with double chokes, RW-FW (left), FW-RW (right) (reproduced from [28]) and (B) monopole antenna with dual rings (reproduced from [100]).

the floating sleeve and the outer conductor. Yang et al. [31] found that these two waves could have a similar amplitude and reversed phase in the area towards the tail of the antenna when the length of the sleeve is roughly half of the effective wavelength by computer simulation. In such a case, the two energy waves can be neutralized and result in the complete attenuation of SAR in the antenna tail. After the leaking current is restrained, the tail of the ablation area can be eliminated to make the shape of the ablation zone become more spherical and suitable for treatment. At present, these two effective methods are still widely used in the clinical setting.

A metal cap attached to the tip of the MW antenna is another way to limit the leaking current $[97,99]$. It can increase the capacitance and force MW energy to radiate in a forward direction from the tip; this cap can come in different shapes such as ring, disk, and arrow. It should be noted that the cap can also be used in combination with the floating sleeve or choke for a better performance, for example, the cap-choked antenna proposed in [99], as shown in Fig. 3C.

With success in suppressing backward heating of the antenna with single choke, sleeve, or cap (also called baluns), Hulusi et al. demonstrated that the leaking currents can be further reduced by adding a second choke [28]. As shown in Fig. 4A, there are two antenna structures that consist of a coaxial slot and double chokes of same lengths. The difference lies in how the chokes are combined and in what order. For example, RW-FW and FW-RW, where the RW and FW are the abbreviations of the "reversed" and "forward", standing for the choke reversing and facing the slot, respectively. They concluded in a numerical study that 1) the antenna in RW-FW results in less backward heating and larger SAR value near the antenna tip than that in FW-RW combination or with a single choke and 2) the periodic structure of RW-FW did not improve the SAR level along the antenna.

As shown in Fig. 4B, Yassin et al. proposed a monopole antenna design with dual conductor rings and studied this in a numerical study [100]. These two additional rings can be used as a capacitive cap to enable the antenna to match at the desired frequency band, leading to further reduction in the axial radiation length along the antenna. They showed that the heating pattern of this modified antenna was spherical and independent of the insertion depth. Compared to the simulation results of the monopole antenna, this modified antenna was able to achieve a larger ablation zone and a more focused heating pattern.

Studies suggest that these two novel designs have less backward heating and can achieve a larger ablation zone, yet comprehensive experiments with different tissues under a wide range of input power are still required to verify the feasibility and effectiveness of these designs.

Though the radiation performance of antennas can be effectively improved by the addition of sleeve or choke, there is a shortcoming that the diameter of conventional antennas is inevitably increased; for an antenna to be useful clinically, it must be possible for it to be placed percutaneously. Recently, techniques have been introduced for the reduction of the diameter of conventional antennas by embedding the choke or sleeve within coaxial cables. Specifically, due to the lower permittivity of air, Luyen et al. [35] found that the diameter of 


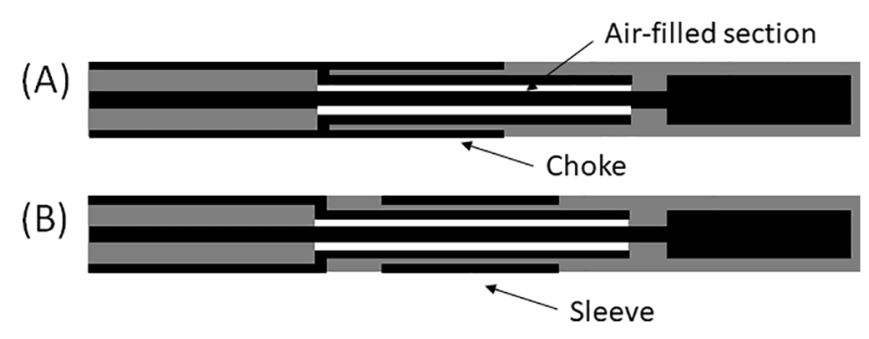

Fig. 5. (A) Modified antennas with the embedded choke (reproduced from [35]), (B) Modified antennas with the embedded sleeve (reproduced from [35]).

conventional antennas can be reduced by using an impedance-matched air-filled coax section at the end of a Teflon-filled coaxial feed line. Then a choke and sleeve are added to the air-filled section respectively without extending the overall coaxial cable diameter. The two designs are shown in Fig. 5A and B, and the performance comparison between the conventional and modified antennas with the choke or floating sleeve in ex vivo porcine tissues is tabulated in Table 1 , where the overall diameter represents the diameter of the antenna.

In the study, the aspect ratio (short diameter vs. long diameter [101]) was used as a measure of the roundness of ablation area; when this ratio is close to 1 , this represents less backward heating. It is notable that although most MWA research and commercial products have focused on operation at the ISM frequencies of $915 \mathrm{MHz}$ and $2.45 \mathrm{GHz}$ [102-104], a few works have systematically analyzed the performance of MWA at higher frequencies $[104,105]$. These works support that it is possible to design shorter and more flexible MW antennas when the higher frequency was used, and potentially realize more spherical thermal lesions all the while producing thermal lesions with volumes comparable to ISM frequencies [106]. However, the cable has a tendency to heat up significantly when the higher frequency is used [104], a factor that needs to be considered in the antenna design before it can be used clinically.

As demonstrated in Table 1, the conventional and modified antennas can achieve a similar ablation zone under the same condition, while the aspect ratio of the modified antennas is better than that of the conventional antennas, which means less backward heating. Furthermore, the diameter of modified antennas is significantly reduced by using this embedding method.

\section{Design of antenna slots}

Increasing the number of slots in a slot antenna is another way to reduce backward heating. The multi-slot antennas can be obtained by cutting several annular slots on the outer conductor and welding the inner and outer conductors at the end of the coaxial cable, as shown in Fig. 6 . The leaking current can be restrained successfully because of the mutual interference between phases of currents from different slots.

Based on simulation results, Keangin et al. $[85,107]$ found that an antenna with a single slot can generate a higher temperature level than that with double slots. Indeed, the double-slot antenna was found to be able to generate a larger and more conformal ablation zone pattern with less backward heating than the single slot antenna, supporting the potential benefit of multi-slot antennas. Two clinical trials of the twoslot antenna can be found in [108]. The targeted tumor was completely covered by the ablation area, showing a satisfactory ablation performance with the two-slot antenna in the clinical setting.

By adjusting the position and length of the slot in multi-slot antennas, different shape and size of ablation zones can be achieved for the treatment of specific tumors. For example, Liu et al. [109] proposed specific model of double slot antenna

which has the capability to form a figure-of-eight ablation pattern. Moreover, dual-slot antennas combined with a choke, a floating metallic sleeve, or a helical slot can also lead to the significant reduction in the backward heating and increase in the energy deposition into tissues $[62,86,101]$.

Wang et al. [39] developed the periodic multi-slot antenna by optimizing the length of slots using a genetic algorithm method achieving a near-spherical ablation zone, with minimal damage to surrounding normal tissues. They concluded that the antenna with ten periodic slots yielded more localized heating and a better conformal ablation zone pattern for spherical tumors when compared to other multi-slot antennas. However, they only selected minimum overtreatment ratio as sole optimization objective for antenna design and neglected the transmission efficiency of the antenna, leading to an ablation area of the optimized multi-slot antenna that was actually smaller than a single slot antenna under the same ablation duration and input power. To improve heating efficiency of multi-slot antennas, Gas [84] proposed to use the $S_{11}$-parameter (representing the efficiency of antennas, discussed below) as the optimization objective to obtain the optimal location and size of slots of multi-slot antennas. But the ablation zone created by the optimized antennas was in a teardrop shape, which might not be suitable for conformal ablation of spherical tumors.

To achieve both near-spherical ablation areas and good heating efficiency, Ge et al. [45] proposed a periodic ten-slot antenna with an $\pi$ impedance matching network, which was used to match the impedance between the antenna and the coaxial line for higher heating efficiency. For optimization objective they also chose the aspect ratio, in other words, aiming for spherical ablation zones. Both simulated and experimental ablation results showed this antenna had a better performance in generating larger and more conformal ablation zones.

By simulation, Xu et al. [44] further demonstrated that the aperiodic structure of slots could have a better performance than the periodic

\section{(A)}

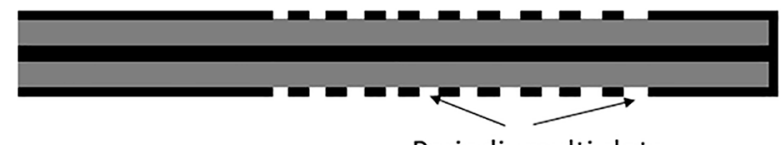

(B)

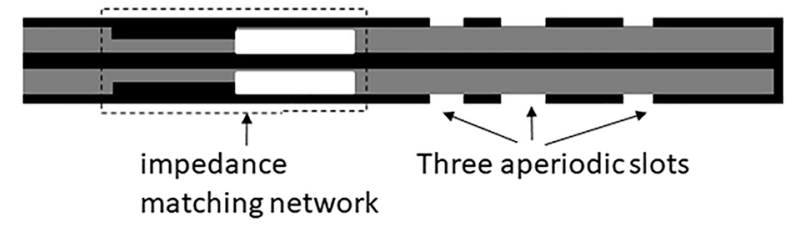

Fig. 6. (A) Periodic multi-slot antenna (reproduced from [39]), (B) Aperiodic tri-slot antenna (reproduced from [44]) (white: air).

Table 1

Experiment results of the conventional and modified antennas with the choke and floating sleeve in ex vivo porcine muscle (adapted from [35]).

\begin{tabular}{|c|c|c|c|c|c|c|}
\hline Antenna & $\begin{array}{l}\text { Frequency } \\
(\mathrm{GHz})\end{array}$ & $\begin{array}{l}\text { Power } \\
\text { (W) }\end{array}$ & $\begin{array}{l}\text { Time } \\
\text { (min) }\end{array}$ & $\begin{array}{l}\text { Overall diameter } \\
(\mathrm{mm})\end{array}$ & $\begin{array}{l}\text { Ablation zone } \\
\left(\mathrm{cm}^{2}\right)\end{array}$ & Aspect ratio \\
\hline Conventional choked dipole & 7 & 30 & 5 & 3.5 & $4.1 \times 2.7$ & 0.66 \\
\hline Modified choked dipole & 7 & 30 & 5 & 2.5 & $4.0 \times 2.8$ & 0.70 \\
\hline Conventional floating sleeve dipole & 7 & 30 & 5 & 3.5 & $4.3 \times 2.8$ & 0.65 \\
\hline Modified floating sleeve dipole & 7 & 30 & 5 & 2.5 & $3.7 \times 2.8$ & 0.76 \\
\hline
\end{tabular}


Table 2

Simulated results of the proposed multi-slot antennas in liver tissues with a frequency of $2.45 \mathrm{GHz}$.

\begin{tabular}{|c|c|c|c|c|c|c|c|}
\hline Antenna & $\begin{array}{l}\text { Power } \\
\text { (W) }\end{array}$ & $\begin{array}{l}\text { Time } \\
\text { (min) }\end{array}$ & $\begin{array}{l}\text { Overall Diameter } \\
(\mathrm{mm})\end{array}$ & $\begin{array}{l}\text { Reflection coefficient } \\
\text { (dB) }\end{array}$ & Ablation Zone $\left(\mathrm{cm}^{2}\right)$ & Aspect Ratio & Ref. \\
\hline Periodic ten-slot & 45 & 10 & 3 & - & $3.81 \times 3.77$ & 0.99 & [39] \\
\hline Single-slot & 30 & 10 & 2.6 & -21.5 & $3.30 \times 4.42$ & 0.74 & [45] \\
\hline$\pi$-matched periodic ten-slot & 30 & 10 & 2.6 & -23.5 & $3.69 \times 3.75$ & 0.98 & [45] \\
\hline$\pi$-matched aperiodic tri-slot & 45 & 10 & 1.79 & -22.3 & $5.27 \times 5.15$ & 0.98 & [44] \\
\hline
\end{tabular}

(A)

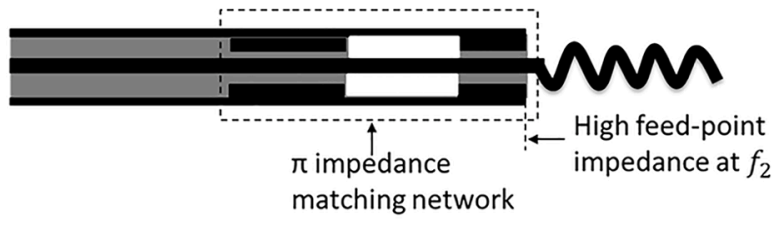

(B)

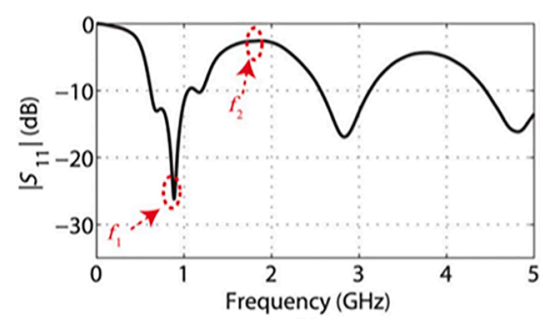

Fig. 7. (A) Helical antenna without baluns (reproduced from [41]), (B) Simulated $\left|S_{11}\right|$ of the antenna with the reference plane placed at the base of the helix (the first resonant frequency $f_{1}=0.9 \mathrm{GHz}$, and the second resonant frequency $f_{2}=1.9 \mathrm{GHz}$ ) [41] (with the permission of IEEE).

structure. They found that the optimized aperiodic tri-slot antenna had a competitive roundness (circularity: 0.92 vs. 0.99) with the optimized periodic ten-slot antenna, but much higher roundness (circularity: 0.92 vs. 0.66) than the periodic tri-slot antennas under the same conditions. To further improve heating efficiency, they also combined an $\pi$ matching network with the aperiodic tri-slot coaxial antenna (Fig. 6B). The simulation results showed that the $\pi$-matched aperiodic tri-slot antenna generated a larger ablation zone with a similar roundness compared to the optimized periodic ten-slot antenna. Besides the competitive ablation performance, the tri-slot antenna is more easily fabricated than the ten-slot antenna.

The comparison of the simulation results between the proposed multi-slot antennas and the single-slot antennas in liver tissues with a frequency of $2.45 \mathrm{GHz}$ is tabulated in Table 2. It shows that the multislot antennas can achieve a more conformal ablation zone than is seen with the single-slot antenna. Multi-slot antennas with a $\pi$ matching network can realize high heating efficiency and near-spherical ablation zone which is suitable for therapy of spherical tumors. Furthermore, the aperiodic structure of multi-slot antenna might have better performance in achieving large ablation zones than the periodic ones.

\section{Balun-free operation}

To achieve the purpose of choking the electric currents excited on the outer conductors without increasing its invasiveness, Luyen et al. [41] proposed a novel balun-free helical antenna, as shown in Fig. 7A. Unlike the normal monopole antenna, this antenna has a helical structure on its terminal end, which has the effect of reducing the length of the antenna (mentioned above). In general, a smaller $S_{11}$ at operating frequency is preferable, because it means a higher power transmission efficiency. However, Luyen et al. found that the SAR pattern of the balun-free antenna under the first resonant frequency $f_{1}$ exhibits long tails along the shaft of the antenna toward the input of the coaxial line, which would cause unwanted heating of the healthy tissue along the antenna shaft.
Table 3

Comparison of matched balun-free helical antenna and floating sleeve dipole antenna [41].

\begin{tabular}{cllllll}
\hline Antenna & $\begin{array}{l}\text { Power } \\
(\mathrm{W})\end{array}$ & $\begin{array}{l}\text { Frequency } \\
(\mathrm{GHz})\end{array}$ & $\begin{array}{l}\text { Overall } \\
\text { diameter } \\
(\mathrm{mm})\end{array}$ & $\begin{array}{l}\text { Time } \\
(\mathrm{min})\end{array}$ & $\begin{array}{l}\text { Ablation } \\
\text { zone } \\
\left(\mathrm{cm}^{2}\right)\end{array}$ & $\begin{array}{l}\text { Aspect } \\
\text { ratio }\end{array}$ \\
\hline $\begin{array}{c}\text { Matched } \\
\text { balun- } \\
\text { free }\end{array}$ & 42 & 1.9 & 3.2 & 5 & $5.5 \times 3$ & 0.55 \\
$\begin{array}{c}\text { helical } \\
\text { antenna }\end{array}$ & 42 & 1.9 & 3.2 & 10 & $7.5 \times 4.3$ & 0.57 \\
$\begin{array}{c}\text { Floating } \\
\text { sleeve } \\
\text { dipole } \\
\text { antenna }\end{array}$ & 42 & 1.9 & 3.5 & 5 & $5.7 \times 3.4$ & 0.60 \\
\hline
\end{tabular}

But at the second resonant frequency $f_{2}$, the SAR pattern was found highly localized [41]. Fig. 7B shows the simulated reflection coefficient of the antenna with the reference plane placed at the helix base (Fig. 7B). This is because the minimum current occurs at the feed point of the helix at this frequency, acting as a natural choke to restrain the leaking currents on the outer surface of the outer conductor of the coaxial cable. However, this area of minimal current results in a high feed-point impedance problem, causing inefficient energy transmission.

This could be addressed by introducing an impedance matching section between the antenna and the coaxial line. The proposed helical antenna was designed to operate at $1.9 \mathrm{GHz}$ due to the lack of microwave power generator at the ISM frequencies as claimed in [41]. Then, the prototype of this balun-free helical antenna implemented with the $\pi$-matching network was fabricated to test and compare its ablation effects with the floating sleeve dipole antennas in [41].

The experimental results of this study using ex vivo bovine liver samples are shown in Table 3. The ablation performance of the helical antenna is comparable to that of the floating sleeve dipole antennas regardless the ablation time but with a smaller antenna diameter (3.2 vs. $3.5 \mathrm{~mm}$ ). Compared with the antennas that use coaxial baluns, the helical antenna showed promise as an alternative to existing MW antennas for reducing the overall diameter of the interstitial antenna. Furthermore, Luyen et al. [41] claimed that the usage of the second resonant frequency can be also applied to monopole antennas with an arbitrary

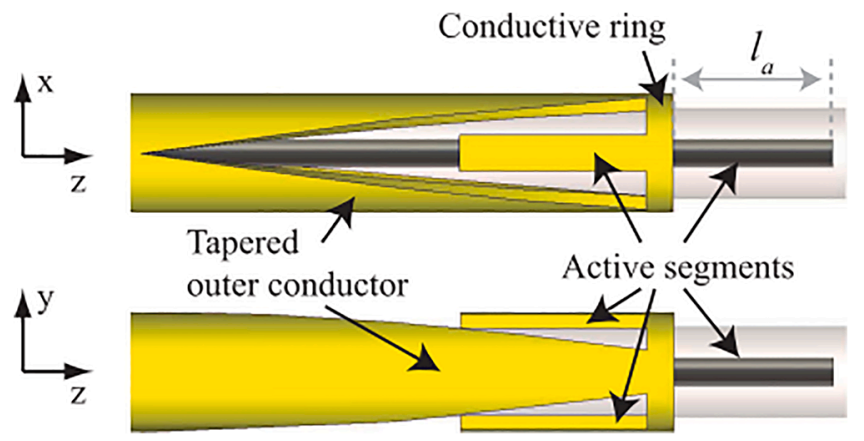

Fig. 8. Antenna with a double-slot tapered balun [38] (with the permission of IEEE). 


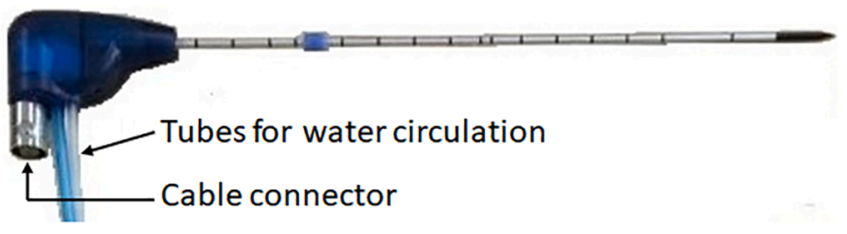

Fig. 9. A commercially available water-cooled microwave antenna (MTC-3CAII37, Nanjing Viking Jiuzhou Medical Equipment Co., Ltd).

shape of inner conductors.

\section{Structure design of outer conductor}

Besides methods mentioned above, the backward heating can also be addressed by changing the outer conductor structure of the coaxial cable because the reverse currents exist due to the unbalanced structure of the coaxial line. Fig. 8 shows a dipole antenna with a double-slot tapered balun [38]. One arm of the dipole was the two parallel strips located in the two slots, which were formed by gradually tapering the outer conductor of the coaxial cable, while the other one was the extension section of the inner conductor. These two arms of the antenna were able to balance the total currents at the operating frequency of the balun, so that the backward heating was effectively restrained. Experimental results on the use of this antenna prototype in ex vivo bovine livers showed that this antenna can generate a more conformal ablation zone compared to the conventional floating sleeve dipole antenna ( 0.76 vs. $0.65)$ with a much smaller antenna diameter (2.6 vs. $3.5 \mathrm{~mm}$ ) [35,38]. However, this particular design exhibits a better impedance matching from 5 to over $8 \mathrm{GHz}$ than the clinical used $2.45 \mathrm{GHz}$.

\section{Addition of cooling system}

The addition of a cooling system to the antenna is another effective way to address the backward heating problem [110-112]. A cooling system has been used in various commercially available MW antennas with favorable clinical outcomes $[113,114]$. There are two types of cooling antennas available in clinic: the gas-cooled antennas [113-115] and water-cooled antennas [116-118]. A typical cooling antenna is shown in Fig. 9. In addition to addressing the backward heating problem, the technique of the cooling system in the antenna can suppress the unwanted heating in tissue from inside the antenna shaft (because of the above-mentioned impedance mismatching) and the over-hot ablation zone [46], which should help prevent the collateral damages to the normal tissues. By eliminating excessive heat mentioned above, the cooling system also can enhance the energy deposition ability of the antenna [46], so that the larger ablation zone can be expected due to more energy deposition. It is noteworthy that to minimize the electromagnetic loss caused by the cooling system during MWA, the material of coolant should be selected carefully. The addition of a cooling channel does inevitably increase the size of the original antenna (e.g. $2.46 \mathrm{vs.}$ $0.86 \mathrm{~mm}[40]$ ). Though this issue can be alleviated by using less coolant flow or antennas with original smaller diameter, the cooling and energy handling capabilities can also be weakened, which should be taken into consideration in the process of conceptual design of antennas.

\section{Designs to fulfill the directional ablation}

In most MWA procedures, a spherically symmetric ablation zone pattern is desirable and expected with a single antenna inserted into the center of the target tissue. Sometimes, multiple antennas are needed to achieve such an ablation zone in a larger dimension. Regardless, there is always the potential for damage to nearby critical structures such as blood vessels or bile ducts. One possible way to address this issue was proposed by Kitchin et al. [119], at which fluid was injected by an
(A)

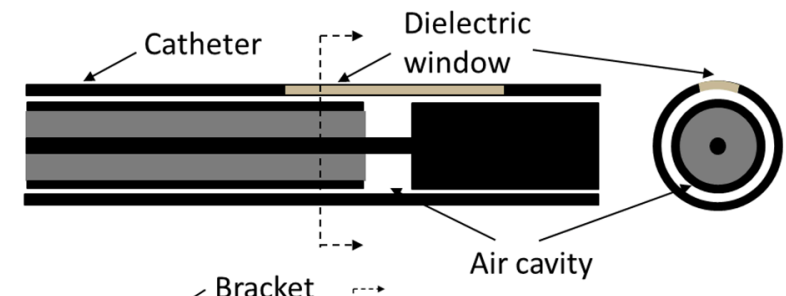

(B)

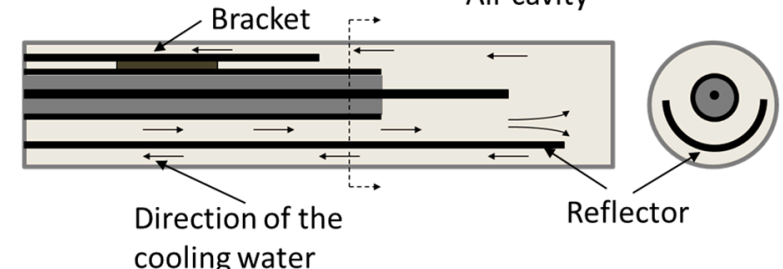

(C)

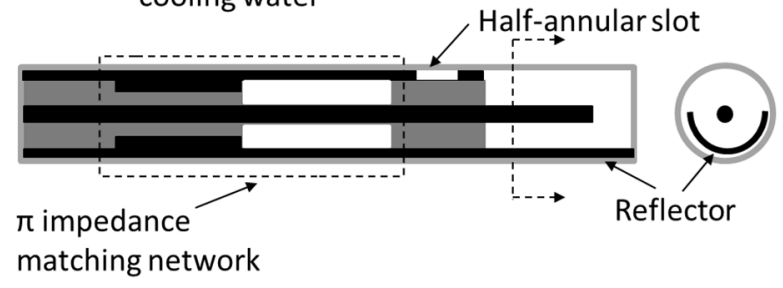

Fig. 10. Directional antennas: (A) Dipole directional antenna (reproduced from [42]), (B) monopole directional antenna with water cooling (reproduced from [43]) and (C) hybrid slot/monopole directional antenna (reproduced from [91]) (white: air).

image-guided needle between the target tissue and the surrounding normal tissues. However, this method requires experienced radiologists and causes additional burden to patients with the deep insertion of an extra needle.

On the other hand, this collateral damage might be avoided by using a so-called directional antenna that can restrict the direction of the MW energy delivery. Directional antennas are characterized by a reflector that can make the power radiate in a certain direction; this reflection can be achieved by the addition of an additional metal catheter or outer conductor on the coaxial cable. To the best of authors' knowledge, the directional antenna is still at the stage of laboratory investigation, and no commercial ones are yet available. As shown in Fig. 10, there are three types of directional antennas being investigated in literature. Fig. 10A shows a dipole antenna with directive radiation [42], which is realized by inserting the dipole antenna into a catheter with an opening that exposes 300 degrees of the circumference of the active portion of the antenna. The metal catheter is then used to guide the microwave energy through the ceramic active window. The air cavity between the outer conductor and the catheter was used for water cooling cycle. It was shown that this antenna can successfully achieve the directional ablation and its SAR patterns are uneven on the opposite sides. Nevertheless, this design has the drawback of being a relatively large antenna diameter. Besides, the heating on the non-active side was not well constrained, its depth could be nearly half of the heating depth on the active side.

As shown in Fig. 10B, McWilliams et al. [43] described a monopole antenna incorporating a hemi-cylindrical reflector. In the design, the monopole antenna was inserted into a stainless-steel tube and fixed by a bracket. One end of the stainless-steel tube near the antenna tip was cut into a semi-cylindrical shape, acting as a reflector to direct the microwave energy to the desired side. The other end of the tube was secured to a homeostatically-controlled valve for water cooling. A 3.5-mm (outer diameter) polyimide catheter was placed over the stainless-steel tube for protection. This antenna can realize almost minimal radiation of energy behind the reflector, but it also had the problem of larger overall diameter and relatively small power deposition within tissues. Sebek et al. [120] investigated the monopole radiating tip and reflector shape of this directional antenna to reduce the antenna diameter and yield a 


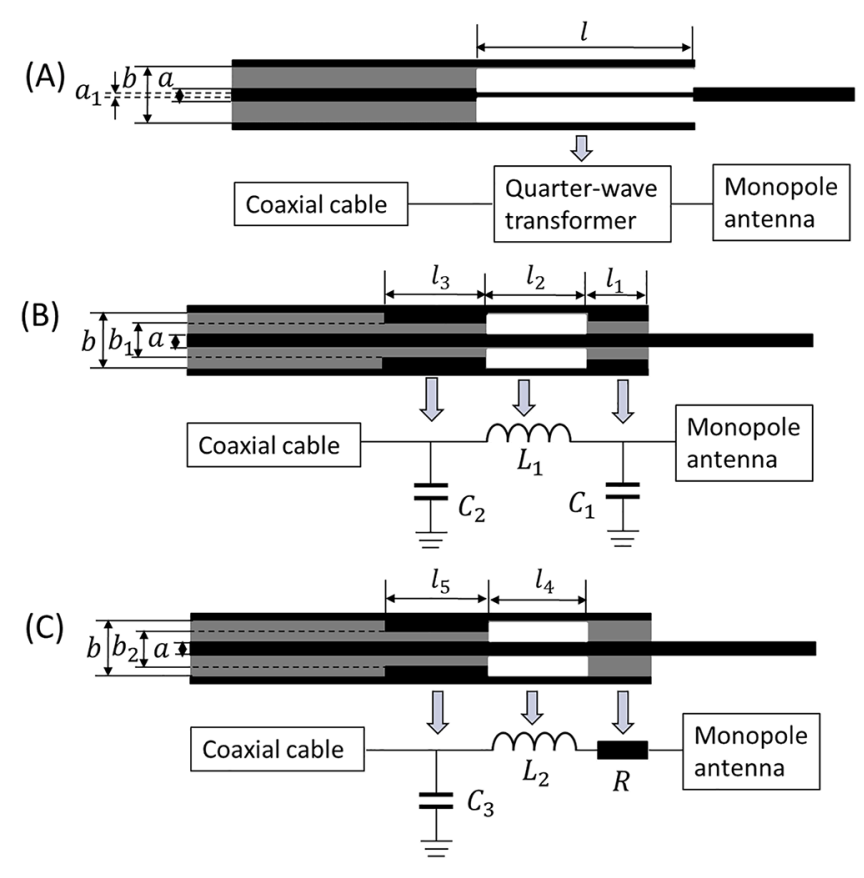

Fig. 11. (A) Quarter-wave transformer (reproduced from [41]), (B) $\pi$ type impedance matching network (reproduced from [45]), (C) L type impedance matching network (reproduced from [127]) (white: air).

larger ablation zone. Antennas were modified by moving the radiating tip closer to the catheter inner-wall and hence closer to the tissue. With such a configuration, it was possible to reduce the diameter of the antenna yet increase the ablation depth compared to the antenna proposed in [43]. Recently, Austin et al. [121] carried out preliminary experiments in ex vivo and in vivo porcine liver tissues using the prototype antenna originally reported by McWilliams et al. [43]. The study further demonstrates that the directional MW antenna has the potential to safely treat the tumors in sensitive areas, like the lungs or adrenal glands, while reducing the risk of collateral injury.

Fig. 10C illustrates a monopole antenna with a portion of its outer conductor used as a reflector [91]. A semi-cylindrical slot is etched in the outer conductor to increase the field in desired direction and decrease the field behind the reflector. As an additional benefit, the reflector and slot can suppress the backward heating along the shaft of the antenna, thus avoiding the presence of the sleeve or choke. The problem of the impedance mismatch which is predominantly caused by the appearance of the semi-cylindrical reflector is resolved by using an internal matching network. This design has near four times overall ablation efficiency higher than that of the antenna proposed in [43], and a smaller overall diameter because an additional tube is not needed for cooling water.

\section{Designs to improve the efficiency}

One way to enhance MWA efficiency is nanoparticle-based therapeutic approach, such as magnetic nanoparticles and liposomes, which can be used as heat sources and reduce input power significantly to produce a similar ablation [122-124]. Another is to optimize the internal structure of the antenna to improve its power transmission efficiency, making more energy deposited into the tissue. In the MW antenna designs, a small value of reflection coefficient $\left(S_{11}\right)$ is preferred because a higher $S_{11}$ indicates less electromagnetic power deposited into the tissue, which is caused by the impedance mismatch between the coaxial cable and the antenna [44]. This mismatch phenomenon can cause additional heating damage to both surrounding tissues and the antenna. If the value of $S_{11}$ is greater than $-10 \mathrm{~dB}$, more than $30 \%$ of the input power will be reflected back toward the microwave generator, which does not meet the general requirements of antenna design [125].

Unlike the antennas with the choke, sleeve and/or cap, which are found with a better impedance match $[100,126,127]$, some antennas (e. g., monopole antennas) may not have a favorable impedance matching condition if they are not also specially designed for a low reflection coefficient. This is something that must be addressed to ensure a good ablation performance and to avoid failure of these antennas midprocedure. Since the lossless transmission line can be used to synthesize an arbitrary impedance according to the transmission line theory, one effective method is to change a section of coaxial cable into the impedance matching network for impedance match between the coaxial line and the antenna. At present, there are mainly three types of matching networks that are commonly used in the design of antennas.

The first design of the matching network is to use a quarterwavelength transformer, as shown in Fig. 11A. The length of the transformer is a quarter of the wavelength, and the characteristic impedance $\left(Z_{01}\right)$ can be given as:

$Z_{01}=\sqrt{Z_{0} Z_{i n}}$

where $Z_{0}$ and $Z_{\text {in }}$ are the characteristic impedance of the load impedance and the feeding coaxial line, respectively [41].

Furthermore, $Z_{01}$ can also be depicted by the quarter-wavelength transformer as:

$Z_{01}=\sqrt{\frac{L}{C}}$

$C=l \frac{2 \pi \varepsilon}{\ln \left(\frac{b}{a_{1}}\right)}, L=l \frac{\mu}{2 \pi} \ln \left(\frac{b}{a_{1}}\right)$

where $C$ and $L$ represent the capacitance and the inductance of the quarter-wavelength transformer, respectively, $l$ is the length of the transformer part, $\varepsilon$ and $\mu$ are the permittivity and permeability of the dielectric, respectively, $a_{1}$ and $b$ are the outer diameter of the inner conductor and the inner diameter of the outer conductor of the transformer, respectively.

The second existing design is a $\pi$ type impedance matching network, which is equivalent to two capacitors $\left(C_{1}\right.$ and $\left.C_{2}\right)$ in parallel with a inductor $\left(L_{1}\right)$ in series [45], as shown in Fig. 11B. The capacitor can be obtained by thickening the outer conductor of the coaxial cable, which decreases the impedance of the impedance matching network. The inductor was designed by removing the dielectric material between the inner conductor and the outer conductor in a short section of the coaxial cable, which can increase the impedance of the impedance matching network. To get a better impedance match, the values of $C_{1}, C_{2}$ and $L_{1}$ can be determined by

$C_{1}=l_{1} \frac{2 \pi \varepsilon}{\ln \left(\frac{b_{1}}{a}\right)}, C_{2}=l_{3} \frac{2 \pi \varepsilon}{\ln \left(\frac{b_{1}}{a}\right)}, L_{1}=l_{2} \frac{\mu}{2 \pi} \ln \left(\frac{b}{a}\right)$

where $l_{1}, l_{2}$ and $l_{3}$ are the component lengths of each part of $\pi$ impedance matching network, as shown in Fig. 11(B), $b_{1}$ is the inner diameter of the thickened outer conductor of the $\pi$ matching network part and $a$ is the inner diameter of the coaxial cable.

The third existing matching network used is the $L$ type one, which is equivalent to an inductor and a resistor in series with a parallel capacitor [127], as shown in Fig. 11C. Similarly, the values of $C_{3}, L_{2}$ and $R$ can be determined by

$C_{3}=l_{5} \frac{2 \pi \varepsilon}{\ln \left(\frac{b_{2}}{a}\right)}, L_{2}=l_{4} \frac{\mu}{2 \pi} \ln \left(\frac{b}{a}\right)$

where $l_{4}$ and $l_{5}$ are the component lengths of each part of $\mathrm{L}$ matching network, as shown in Fig. $11 \mathrm{C}$, and $b_{2}$ is the inner diameter of the thickened outer conductor of the L matching network part.

According to Eqns. (10)-(12), it is not difficult to find that the impedance matching networks of these three designs are all related to 


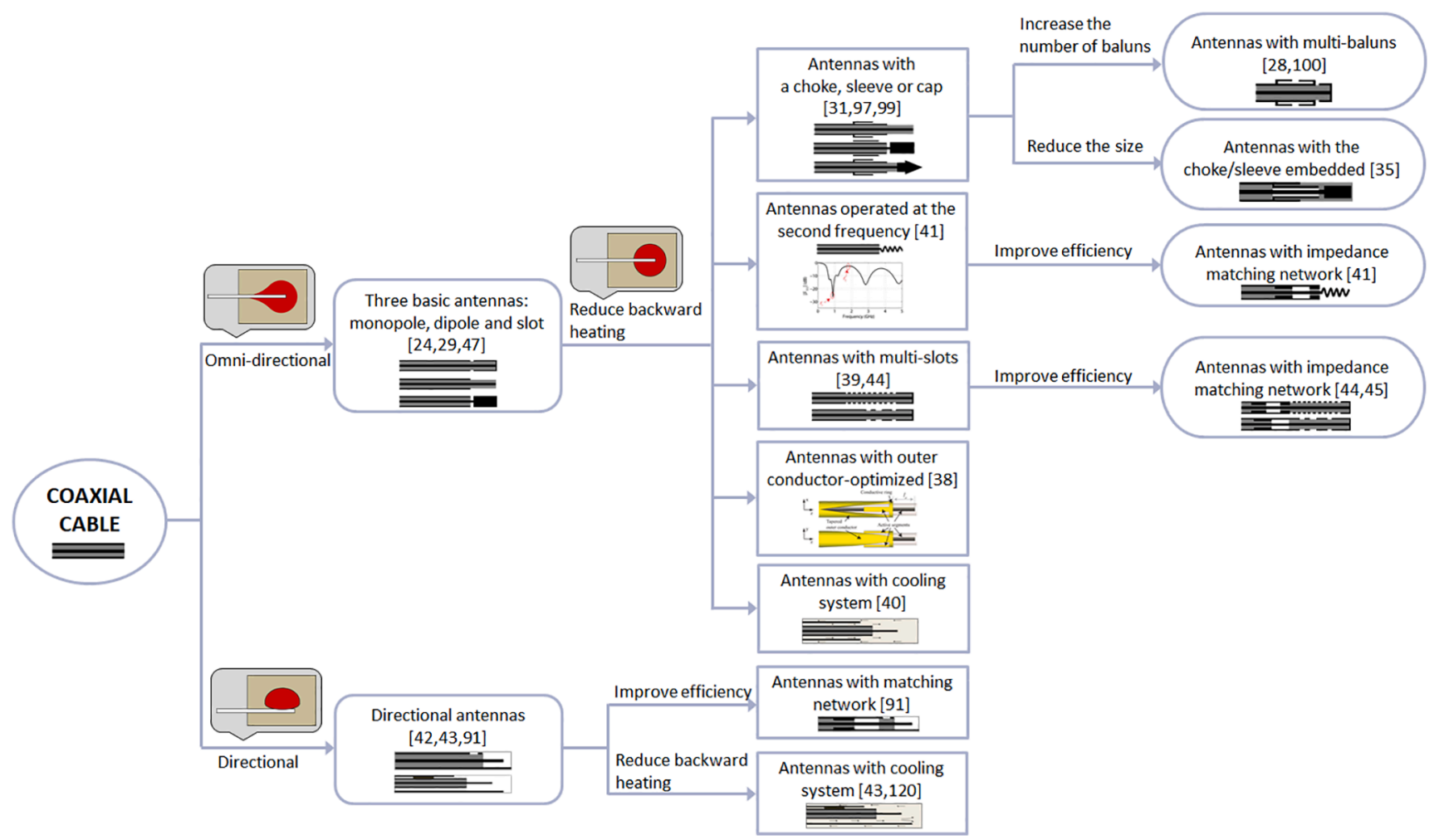

Fig. 12. Development diagram of the existing MW antennas for MWA.

the component dimensions of the networks (i.e., the length and diameter), which provides the opportunity to optimize the structure of antennas for the optimal matching performance. However, these designs increase the difficulty in the manufacturing process, especially the $\pi$ impedance matching network, which may be addressed with the advanced micro manufacture technique.

To sum up, the panorama of MW antenna evolution reviewed in this study is illustrated in Fig. 12.

\section{Conclusion}

The MW antenna plays a vital role in the ablation of tumors, and many different types of MW antennae have been developed. A great deal of progress in the development of MW antennas has been made in response to various clinical requirements. This paper reviews the stateof-the-art of antenna designs and summarizes approaches for achieving three design criteria of the antenna to help invente novel antennas to advance this promising ablation technique to become an effective and safe and widely used modality in the treatment of patients with cancer.

\section{Funding}

This work was partially supported by National Natural Science Foundation of China under Grant 81801795.

\section{Declaration of Competing Interest}

The authors declare that they have no known competing financial interests or personal relationships that could have appeared to influence the work reported in this paper.

\section{References}

[1] Izzo F, Granata V, Grassi R, et al. Radiofrequency Ablation and Microwave Ablation in Liver Tumors: An Update. Oncologist 2019;24(10):E990-1005.
[2] Prud'homme C, Deschamps F, Moulin B, et al. Image-guided lung metastasis ablation: a literature review. Int J Hyperthermia 2019;36(2):37-45.

[3] Anglickis M, Anglickiene G, Andreikaite G, et al. Microwave thermal ablation versus open partial nephrectomy for the treatment of small renal tumors in patients over 70 years old. Medicina 2019;55(10):664.

[4] Fan QY, Zhou Y, Zhang MH, et al. Microwave Ablation of Primary Malignant Pelvic Bone Tumors. Front Surgery 2019;6:5.

[5] Lu A, Woodrum DA, Felmlee JP, et al. Improved MR-thermometry during hepatic microwave ablation by correcting for intermittent electromagnetic interference artifacts. Phys Med-Eur J Med Phys 2020;71:100-7.

[6] Gorny KR, Favazza CP, Lu A, et al. Practical implementation of robust MRthermometry during clinical MR-guided microwave ablations in the liver at $1.5 \mathrm{~T}$. Phys Med-Eur J Med Phys 2019;67:91-9.

[7] Paul J, Vogl TJ, Chacko A. Dual energy computed tomography thermometry during hepatic microwave ablation in an ex-vivo porcine model. Phys Med-Eur J Med Phys 2015;31(7):683-91.

[8] Hui TCH, Brace CL, Hinshaw JL, et al. Microwave ablation of the liver in a live porcine model: the impact of power, time and total energy on ablation zone size and shape. Int J Hyperthermia 2020;37(1):668-76.

[9] Head HW, Dodd GD. Thermal ablation for hepatocellular carcinoma. Gastroenterology 2004;127(5):S167-78.

[10] Deshazer G, Prakash P, Merck D, et al. Experimental measurement of microwave ablation heating pattern and comparison to computer simulations. Int $\mathrm{J}$ Hyperthermia 2017;33(1):74-82.

[11] Simon CJ, Dupuy DE, Mayo-Smith WW. Microwave ablation: principles and applications. Radiographics 2005;25:S69-84.

[12] Ahmed M, Brace CL, Lee FT, et al. Principles of and advances in percutaneous ablation. Radiology 2011;258(2):351-69.

[13] Gao X, Tian Z, Cheng YY, et al. Experimental and numerical study of microwave ablation on ex-vivo porcine lung. Electromagn Biol Med 2019;38(4):249-61.

[14] Lopresto V, Pinto R, Lodato R, et al. Design and realisation of tissue-equivalent dielectric simulators for dosimetric studies on microwave antennas for interstitial ablation. Phys Med-Eur J Med Phys 2012;28(3):245-53.

[15] Chu KF, Dupuy DE. Thermal ablation of tumours: biological mechanisms and advances in therapy. Nat Rev Cancer 2014;14(3):199-208.

[16] Kim C. Understanding the nuances of microwave ablation for more accurate posttreatment assessment. Future Oncol 2018;14(17):1755-64.

[17] Tafti BA, Genshaft S, Suh R, et al. Lung ablation: indications and techniques. Semin Intervent Radiol 2019;36(3):163-75.

[18] Kok HP, Cressman ENK, Ceelen W, et al. Heating technology for malignant tumors: a review. Int J Hyperthermia 2020;37(1):711-41.

[19] Ashour AS, Asran M, Fotiadis DI, Optimal power for microwave slotted probes in ablating different hepatocellular carcinoma sizes. Comput Biol Med. 1272020 104101104101.

[20] Lubner MG, Brace CL, Ziemlewicz TJ, et al. Microwave ablation of hepatic malignancy. Semin Intervent Radiol 2013;30(1):56-66. 
[21] Gao HJ, Wang XR, Wu SC, et al. Conformal coverage of liver tumors by the thermal coagulation zone in 2450-MHz microwave ablation. Int J Hyperthermia 2019;36(1):591-605.

[22] Tehrani MHH, Soltani M, Kashkooli FM, et al. Use of microwave ablation for thermal treatment of solid tumors with different shapes and sizes-A computational approach. PLoS One 2020;15(6).

[23] Shamekhi L, Sayehvand H-O, Karami H. Tumour shape-dependent microwave hyperthermia using a novel coaxial micro-cut slot antenna. J Therm Biol 2020;88

[24] Hurter W, Reinbold F, Lorenz WJ. A dipole antenna for interstitial microwave hyperthermia. IEEE Trans Microwave Theory Tech 1991;39(6):1048-54.

[25] Labonte S, Ali HO, Roy L. Monopoles for microwave catheter ablation of heart tissue. IEEE MTT-S Int Microwave Sympos 1995;1:303-6.

[26] Wu MS, Ito K, Kasai H. Analysis of current and electric field distributions of coaxial-slot antenna for interstitial microwave hyperthermia. J Electromagn Waves Appl 1995;9(5-6):831-49.

[27] Mohtashami Y, Luyen H, Hagness SC, et al. Non-coaxial-based microwave ablation antennas for creating symmetric and asymmetric coagulation zones. J Appl Phys 2018;123(21):214903.

[28] Acikgoz H, Mittra R, Ieee. Microwave Coaxial Antenna for Cancer Treatment: Reducing the Backward Heating Using a Double Choke. ISAP. 2015:1-4.

[29] Fallahi H, Prakash P. Antenna designs for microwave tissue ablation. Crit Rev Biomed Eng. 2018;46(6):495-521.

[30] Icheln C, Krogerus J, Vainikainen P. Use of balun chokes in small-antenna radiation measurements. IEEE Trans Instrum Meas 2004;53(2):498-506.

[31] Yang DS, Bertram JM, Converse MC, et al. A floating sleeve antenna yields localized hepatic microwave ablation. IEEE Trans Biomed Eng. 2006;53(3): 533-7.

[32] Maini S. Design optimization of tapered cap floating sleeve antenna for interstitial microwave ablation for liver tumor. ICCE 2016:1-4.

[33] Hassan E, Takruri-Rizk H, Hope M. Applicator design considerations of microwave tumor ablation. CSNDSP 2016,:1-6.

[34] Neagu V. A study of microwave ablation antenna optimization. EHB 2017:41-4.

[35] Luyen H, Hagness SC, Behdad N. Reduced-diameter designs of coax-fed microwave ablation antennas equipped with baluns. IEEE Antennas Wirel Propag Lett 2017;16:1385-8.

[36] Wakaki T, Michiyama T, Kuwano S. A new interstitial choke embedded antenna for microwave ablation. IEICE Commun Express 2017;6(7):435-8.

[37] Maini S, Shekhawat DS. Analysis of copper tube sleeve coaxial spiral antenna for interstitial hepatic microwave ablation. ICIST 2018:31-4.

[38] Hung LY, Hagness SC, Behdad N. A minimally invasive coax-fed microwave ablation antenna with a tapered balun. IEEE Trans Antennas Propag 2017;65(12): 7280-7.

[39] Wang T, Zhao G, Qiu BS. Theoretical evaluation of the treatment effectiveness of a novel coaxial multi-slot antenna for conformal microwave ablation of tumors. Int J Heat Mass Transf 2015;90:81-91.

[40] Fallahi H, Clausing D, Shahzad A, et al. Microwave antennas for thermal ablation of benign adrenal adenomas. Biomed Phys Eng Express 2019;5(2).

[41] Luyen H, Hagness SC, Behdad N. A balun-free helical antenna for minimally invasive microwave ablation. IEEE Trans Antennas Propag 2015;63(3):959-65.

[42] Alnassan H, Kastler A, Wang X, et al. Modified dipole antenna for directional microwave ablation using 3D numerical simulation. BEIC 2014:1-4.

[43] McWilliams BT, Schnell EE, Curto S, et al. A directional interstitial antenna for microwave tissue ablation: theoretical and experimental investigation. IEEE Trans Biomed Eng 2015;62(9):2144-50.

[44] Xu YS, Moser MAJ, Zhang E, et al. Large and round ablation zones with microwave ablation: A preliminary study of an optimal aperiodic tri-slot coaxial antenna with the pi-matching network section. Int J Therm Sci 2019;140:539-48.

[45] Ge MK, Jiang HJ, Huang XY, et al. A multi-slot coaxial microwave antenna for liver tumor ablation. Phys Med Biol. 2018;63(17):175011.

[46] Brace CL. Microwave tissue ablation: biophysics, technology, and applications. Crit Rev Biomed Eng. 2010;38(1):65-78.

[47] Bertram JM, Yang D, Converse MC, et al. A review of coaxial-based interstitial antennas for hepatic microwave ablation. Crit Rev Biomed Eng. 2006;34(3): $187-213$.

[48] Tammam E, Said AM, Ibrahim AA, et al. About the interstitial microwave cance ablation: principles, advantages and challenges. IEEE Access 2020;8:49685-94.

[49] Favi E, Raiteri M, Paone G, et al. Microwave ablation of renal cell carcinoma of the transplanted kidney: two cases. Cardiovasc Intervent Radiol 2019;42(11): 1653-7.

[50] Yamada Y, Shiaishi T, Ueno A, et al. Phase I study of cancer lesion-targeted microwave coagulation therapy for localized prostate cancer: A pilot clinical study protocol. Contemp Clin Trials Commun 2019;16:100471.

[51] Zhang TQ, Huang SM, Gu YK, et al. Sequential and simultaneous 4-Antenna microwave ablation in an ex vivo bovine liver model. Cardiovasc Intervent Radiol. 2019;42(10):1466-74.

[52] Dimitri M, Staderini F, Brancadoro M, et al. A new microwave applicator for laparoscopic and robotic liver resection. Int J Hyperthermia. 2019;36(1):75-86.

[53] Iezzi R, Cioni R, Basile D, et al. Standardizing percutaneous Microwave Ablation in the treatment of Lung Tumors: a prospective multicenter trial (MALT study). Eur Radiol 2020.

[54] Scapaticci R, Lopresto V, Pinto R, et al. Monitoring thermal ablation via microwave tomography: an ex vivo experimental assessment. Diagnostics 2018;8 (4):175011.

[55] Lubner MG, Brace CL, Hinshaw JL, et al. Microwave tumor ablation: mechanism of action, clinical results, and devices. J Vasc Interv Radiol. 2010;21(8): S192-203.
[56] Zhou W, Chen YD, Zhang L, et al. Percutaneous microwave ablation of metastatic lymph nodes from papillary thyroid carcinoma: preliminary results. World J Surg, 2019;43(4):1029-37.

[57] Hu YR, Yang ZW, Sun YS. Analysis of the feasibility of microwave ablation for colorectal liver metastases: a preliminary report. Videosurgery Other Miniinvasive Techn 2020;15(1):30-5.

[58] Chiang J, Wang P, Brace CL. Computational modelling of microwave tumour ablations. Int J Hyperthermia 2013;29(4):308-17.

[59] Maini S. FEM simulation of tapered cap floating sleeve antenna for hepatocellular carcinoma therapy. Electromagn Biol Med. 2016;35(2):152-60.

[60] Singh S, Melnik R. Thermal ablation of biological tissues in disease treatment: A review of computational models and future directions. Electromagn Biol Med. 2020;39(2):49-88.

[61] Prakash P. Theoretical modeling for hepatic microwave ablation. Open Biomed Eng J 2010;4:27-38.

[62] Lee M, Son T. Helical slot antenna for the microwave ablation. Int J Antennas Propag 2019;2019:2126879.

[63] Ji Z, Brace CL. Expanded modeling of temperature-dependent dielectric properties for microwave thermal ablation. Phys Med Biol 2011;56(16):5249-64.

[64] Brace CL, Ieee. Temperature-dependent dielectric properties of liver tissue measured during thermal ablation: Toward an improved numerical model. In: Conf Proc IEEE Eng Med Biol Soc.2008:230-3.

[65] Manago R, Saito K. Coagulated region analysis in a microwave surgical device with temperature-dependent physical properties of tissue. Ieice Electronics Express 2019;16(9):1-4.

[66] Pennes HH. Analysis of tissue and arterial blood temperatures in the resting human forearm. J Appl Physiol 1998;85(1):5-34.

[67] Valvano JW, Cochran JR, Diller KR. Thermal conductivity and diffusivity of biomaterials measured with self-heated thermistors. Int J Thermophys 1985;6(3): 301-11.

[68] Sturesson C, Andersson-Engels S. A mathematical model for predicting the temperature distribution in laser-induced hyperthermia. Experimental evaluation and applications. Phys Med Biol 1995;40(12):2037-52.

[69] Selmi M, Bin Dukhyil AA, Belmabrouk H. Numerical analysis of human cancer therapy using microwave ablation. Appl Sci-Basel 2020;10(1):1-15.

[70] Sinha A, Misra JC. Numerical study of flow and heat transfer during oscillatory blood flow in diseased arteries in presence of magnetic fields. Appl Math MechEnglish Ed 2012;33(5):649-62.

[71] Zhang B, Moser MAJ, Zhang EM, et al. A review of radiofrequency ablation: Large target tissue necrosis and mathematical modelling. Phys Med-Eur J Med Phys 2016;32(8):961-71.

[72] Prakash P, Diederich CJ. Considerations for theoretical modelling of thermal ablation with catheter-based ultrasonic sources: Implications for treatment planning, monitoring and control. Int J Hyperthermia 2012;28(1):69-86.

[73] Pearce JA. Models for thermal damage in tissues: processes and applications. Crit Rev Biomed Eng 2010;38(1):1-20.

[74] Pearce J. Relationship between Arrhenius models of thermal damage and the CEM 43 thermal dose. Proc SPIE 2009;7181:718104-15.

[75] Farina L, Weiss N, Nissenbaum Y, et al. Characterisation of tissue shrinkage during microwave thermal ablation. Int J Hyperthermia 2014;30(7):419-28.

[76] Brace CL, Diaz TA, Hinshaw JL, et al. Tissue contraction caused by radiofrequency and microwave ablation: a laboratory study in liver and lung J Vasc Interv Radiol 2010;21(8):1280-6.

[77] Rossmann C, Garrett-Mayer E, Rattay F, et al. Dynamics of tissue shrinkage during ablative temperature exposures. Physiol Meas 2014;35(1):55-67.

[78] Amabile C, Farina L, Lopresto V, et al. Tissue shrinkage in microwave ablation of liver: an ex vivo predictive model. Int J Hyperthermia 2017;33(1):101-9.

[79] Farina L, Nissenbaum Y, Goldberg SN, et al. Tissue shrinkage in microwave ablation: ex vivo predictive model validation. In: 2018 2nd URSI Atlantic Radio Science Meeting (AT-RASC); 2018. p. 1-4.

[80] Ortega-Palacios R, Trujillo-Romero CJ, Cepeda-Rubio MFJ, et al. Heat transfer study in breast tumor phantom during microwave ablation: modeling and experimental results for three different antennas. Electronics 2020;9(3):535.

[81] Guerrero Lopez GD, Jesus Cepeda Rubio MF, Hernandez Jacquez JI, et al. Computational FEM model, phantom and ex vivo swine breast validation of an optimized double-slot microcoaxial antenna designed for minimally invasive breast tumor ablation: theoretical and experimental comparison of temperature, size of lesion, and SWR, preliminary data. Comput Math Methods Med. 2017; 2017.

[82] Gas P, Szymanik B. Shape optimization of the multi-slot coaxial antenna for local hepatic heating during microwave ablation. IIPhDW 2018:319-22.

[83] Jiang YX, Zhao JZ, Li WT, et al. A coaxial slot antenna with frequency of $433 \mathrm{MHz}$ for microwave ablation therapies: design, simulation, and experimental research. Med Biol Eng Comput 2017;55(11):2027-36.

[84] Gas P. Optimization of multi-slot coaxial antennas for microwave thermotherapy based on the S11-parameter analysis. Biocybernet Biomed Eng 2017;37(1):78-93.

[85] Keangin P, Rattanadecho P, Wessapan T. An analysis of heat transfer in liver tissue during microwave ablation using single and double slot antenna. In Commun Heat Mass Transfer 2011;38(6):757-66.

[86] Bertram JM, Yang DS, Converse MC, et al. Antenna design for microwave hepatic ablation using an axisymmetric electromagnetic model. Biomed Eng Online 2006; $5: 15$.

[87] Huang C-F, Li C-F, Chao H-Y. The study of SAR distribution in microwave ablation for tumours. APEMC 2015:24-6. 
[88] Chen DD, Du YX, Chen ZB, et al. Computer modeling and in vitro experimental study of water-cooled microwave ablation array. Minim Invasive Ther Allied Technol 2019.

[89] Cavagnaro M, Pinto R, Lopresto V. Numerical models to evaluate the temperature increase induced by ex vivo microwave thermal ablation. Phys Med Biol. 2015;60 (8):3287-311.

[90] Icnirp. Guidelines for Limiting Exposure to Electromagnetic Fields (100 kHz to 300 GHz). Health Phys. 2020;118(5):483-524.

[91] Mohtashami Y, Hagness SC, Behdad N. A hybrid slot/monopole antenna with directional heating patterns for microwave ablation. IEEE Trans Antennas Propag 2017;65(8):3889-96.

[92] Hurter W, Reinbold F. A dipole antenna for interstitial microwave hyperthermia. Microw Theory Techn IEEE Trans 1991;39(6):1048-54.

[93] Etoz S, Brace CL. Analysis of microwave ablation antenna optimization techniques. Int J Rf Microw Comput-Aided Eng 2018;28(3).

[94] Yassin MM, Tammam E, Ibrahim AA, et al. Dielectric-loaded 5.8 GHz interstitial monopole antenna for spherically-shaped hepatic tumors ablation. PIERS-Spring 2019:2529-33.

[95] Hamada L, Wu M-S, Ito K, et al. Basic analysis on SAR distribution of coaxial-slot antenna array for interstitial microwave hyperthermia. IEICE Trans Electron 1995;E78-C(11):1624-31.

[96] Pongpakpien S, Preechaphonkul W, Rattanadecho P. Effects of thermal and electrical properties on porous liver during microwave ablation using microwave coaxial slot antenna. Int J Heat Technol 2020;38(2):361-70.

[97] Nevels RD, Arndt GD, Raffoul GW, et al. Microwave catheter design. IEEE Trans Biomed Eng 1998;45(7):885-90.

[98] Lara JE, Vera A, Leija L, et al. Modeling of electromagnetic and temperature distributions of an intersticial coaxial-based choked antenna for hepatic tumor microwave ablation. CCE 2015:1-5.

[99] Cavagnaro M, Amabile C, Bernardi P, et al. A minimally invasive antenna for microwave ablation therapies: design, performances, and experimental assessment. IEEE Trans Biomed Eng 2011;58(4):949-59.

[100] Yassin MM, Tammam E, Ibrahim AA, et al. A dual ring interstitial monopole antenna with spherical heating pattern for hepatic tumor microwave ablation. Natl Radio Sci Conf 2019:425-30.

[101] Ibitoye ZA, Nwoye EO, Aweda MA, et al. Optimization of dual slot antenna using floating metallic sleeve for microwave ablation. Med Eng Phys. 2015;37(4): 384-91.

[102] Leung U, Kuk D, D’Angelica MI, et al. Long-term outcomes following microwave ablation for liver malignancies. Br J Surg 2015;102(1):85-91.

[103] Curto S, Taj-Eldin M, Fairchild D, et al. Microwave ablation at $915 \mathrm{MHz}$ vs 2.45 GHz: A theoretical and experimental investigation. Med Phys 2015;42(11): $6152-61$.

[104] Sawicki JF, Shea JD, Behdad N, et al. The impact of frequency on the performance of microwave ablation. Int J Hyperthermia 2017;33(1):61-8.

[105] Hung L, Gao F, Hagness SC, et al. Microwave ablation at 10.0 GHz Achieves comparable ablation zones to $1.9 \mathrm{GHz}$ in ex vivo bovine liver. IEEE Trans Biomed Eng 2014;61(6):1702-10.

[106] Sawicki JF, Luyen H, Mohtashami Y, et al. The performance of higher frequency microwave ablation in the presence of perfusion. IEEE Trans Biomed Eng 2019;66 (1):257-62.

[107] Rattanadecho P, Keangin P. Numerical study of heat transfer and blood flow in two-layered porous liver tissue during microwave ablation process using single and double slot antenna. Int J Heat Mass Transf 2013;58(1-2):457-70.
[108] Saito K, Yoshimura H, Ito K, et al. Clinical trials of interstitial microwave hyperthermia by use of coaxial-slot antenna with two slots. IEEE Trans Microwave Theory Tech 2004;52(8):1987-91.

[109] Liu WM, Lin XQ, Yang FS, et al. Microwave ablation antenna with the ablation pattern being a figure-of-eight. IMWS-AMP 2016:1-3.

[110] He N, Wang W, Ji Z, et al. Microwave ablation: an experimental comparative study on internally cooled antenna versus non-internally cooled antenna in liver models. Acad Radiol 2010;17(7):894-9.

[111] Meloni MF, Chiang J, Laeseke PF, et al. Microwave ablation in primary and secondary liver tumours: technical and clinical approaches. Int J Hyperthermia 2017;33(1):15-24.

[112] Knavel EM, Hinshaw JL, Lubner MG, et al. High-powered gas-cooled microwave ablation: shaft cooling creates an effective stick function without altering the ablation zone. Am J Roentgenol. 2012;198(3):W260-5.

[113] Ziemlewicz TJ, Hinshaw JL, Lubner MG, et al. Percutaneous microwave ablation of hepatocellular carcinoma with a gas-cooled system: initial clinical results with 107 tumors. J Vasc Interv Radiol. 2015;26(1):62-8.

[114] Horn JC, Patel RS, Kim E, et al. Percutaneous microwave ablation of renal tumors using a gas-cooled 2.4-GHz probe: technique and initial results. J Vasc Interv Radiol. 2014;25(3):448-53.

[115] Leapman M, Jayadevan R, Phillips C, et al. Percutaneous gas-cooled microwave ablation for small renal masses: the mount sinai experience. J Urol. 2014;191(4): E620.

[116] Kuang M, Lu MD, Xie XY, et al. Liver cancer: Increased microwave delivery to ablation zone with cooled shaft antenna - Experimental and clinical studies. Radiology 2007;242(3):914-24.

[117] Wang Y, Sun YY, Feng L, et al. Internally cooled antenna for microwave ablation: Results in ex vivo and in vivo porcine livers. Eur J Radiol 2008;67(2):357-61.

[118] Zhou Q, Jin X, Jiao DC, et al. Microwave ablation: results in ex vivo and in vivo porcine livers with 2450-MHz cooled-shaft antenna. Chin Med J 2011;124(20): 3386-93.

[119] Kitchin D, Lubner M, Ziemlewicz T, et al. Microwave ablation of malignant hepatic tumours: Intraperitoneal fluid instillation prevents collateral damage and allows more aggressive case selection. Int J Hyperthermia 2014;30(5):299-305.

[120] Sebek J, Curto S, Bortel R, et al. Analysis of minimally invasive directional antennas for microwave tissue ablation. Int J Hyperthermia 2017;33(1):51-60.

[121] Pfannenstiel A, Sebek J, Fallahi H, et al. Directional microwave ablation: experimental evaluation of a $2.45-\mathrm{GHz}$ applicator in ex vivo and in vivo liver. J Vasc Interv Radiol 2020;31(7):1170-7.

[122] Soltani M, Tehrani MHH, Kashkooli FM, et al. Effects of magnetic nanoparticle diffusion on microwave ablation treatment: A numerical approach. J Magn Magn Mater 2020;514.

[123] Minbashi M, Kordbacheh AA, Ghobadi A, et al. Optimization of power used in liver cancer microwave therapy by injection of Magnetic Nanoparticles (MNPs). Comput Biol Med 2020;120.

[124] Wu SS, Zhang DY, Yu J, et al. Chemotherapeutic nanoparticle-based liposomes enhance the efficiency of mild microwave ablation in hepatocellular carcinoma therapy. Front Pharmacol 2020;11.

[125] Sawarbandhe MD, Naik SB, Satpute VR, et al. Coaxial Antenna for Microwave Ablation. International Conference on Distributed Computing, Vlsi, Electrical Circuits and Robotics. 2016:119-122.

[126] Longo I, Gentili GB, Cerretelli M, et al. A coaxial antenna with miniaturized choke for minimally invasive interstitial heating. IEEE Trans Biomed Eng 2003;50(1): $82-8$.

[127] Mohtashami Y, Luyen H, Sawicki JF, et al. Tools for attacking tumors. IEEE Antennas Propag Mag 2018;60(6):52-7. 